\title{
Potentiation of anticonvulsant effect of phenytoin by celecoxib against maximum electroshock induced convulsions in albino rats
}

\author{
Mohammed Naseeruddin Nadeem ${ }^{1 *}$, Maliha Maqdoom² \\ ${ }^{1}$ Department of Pharmacology, Deccan College of Medical Sciences, Hyderabad, Telangana, India \\ ${ }^{2}$ Department of Physiology, Ayaan Institute of Medical Sciences, Moinabad, Telangana, India
}

Received: 15 August 2020

Revised: 28 August 2020

Accepted: 29 August 2020

\section{*Correspondence:}

Dr. Mohammed Naseeruddin Nadeem,

Email:nad040@gmail.com

Copyright: $\odot$ the author(s), publisher and licensee Medip Academy. This is an open-access article distributed under the terms of the Creative Commons Attribution Non-Commercial License, which permits unrestricted non-commercial use, distribution, and reproduction in any medium, provided the original work is properly cited.

\begin{abstract}
Background: Epilepsy, a chronic neurological disorder affects more than $1 \%$ of world population. Despite the availability of a number of antiepileptics, refractoriness to them exists in approximately one third of cases worldwide. Induction of cycloxygenase and increased levels of proinflammatory meditators are seen in epilepsy. P-glycoprotein upregulation due to phenytoin was found to contribute to its pumping out of cell, leading to refractoriness to phenytoin therapy. Also, cycloxygenase-2 inhibitors were found to prevent P-glycoprotein upregulation. Since cycloxygenase-2 inhibition decreases levels of proinflammatory cytokines responsible for neuroinflammation, this study aims to evaluate anticonvulsant effect of celecoxib and also to investigate whether it potentiates the anticonvulsant effect of phenytoin. Methods: Maximum electroshock seizures (MES) were induced in Albino rats using electroconvulsiometer to evaluate tonic convulsions, identified by tonic hind limb extension (THLE) in rats. A delay in onset of THLE and a reduction in duration of THLE were taken as deciding parameters to ascertain anticonvulsive activity. Rats randomly divided into groups, received pretreatment with celecoxib at 3 doses $(10,20,40 \mathrm{mg} / \mathrm{kg})$, phenytoin $(6.25 \mathrm{mg} / \mathrm{kg})$, phenytoin $(12.5$ $\mathrm{mg} / \mathrm{kg}$ ) and combination of phenytoin $(6.25 \mathrm{mg} / \mathrm{kg}$ ) with celecoxib (ED50, i.e. $20 \mathrm{mg} / \mathrm{kg}$ ), before inducing MES seizures and findings compared to control group.

Results: Celecoxib (20 and $40 \mathrm{mg} / \mathrm{kg}$ ) showed significant anticonvulsant effect by MES test. Also, its combination with phenytoin caused significant decrease in the duration of THLE when compared to phenytoin alone at the same dose.

Conclusions: The results of this study indicate that celecoxib potentiates the anticonvulsant effect of phenytoin.
\end{abstract}

Keywords: Celecoxib, Phenytoin, Maximum electroshock test, Prostaglandin E2, P-glycoprotein

\section{INTRODUCTION}

Epilepsy is a chronic neurological disease, which affects more than $1 \%$ of the human population. ${ }^{1}$ It is characterized by a long-lasting tendency to develop epileptic seizures. Epileptic seizures are a consequence of electrical disturbance in the brain, characterized by an imbalance between excitation and inhibition. ${ }^{2}$ There has been considerable progress in the pharmacotherapy of epilepsy over the last few decades, including the introduction of new antiepileptic drugs such as gabapentine, lamotrigine and topiramate. In spite of the currently available therapeutic arsenal of old and new antiepileptic drugs, more than $30 \%$ of patients keep on developing seizures that are refractory to the currently available antiepileptics. According to international league against epilepsy, resistant epilepsy is the epilepsy which occurs when a person has not become seizure free with two anti-epileptic 
drugs. ${ }^{3-6}$ Moreover, current drug therapy of epilepsy is complicated by adverse drug reactions, teratogenic effects and long term toxicities. Among the currently available antiepileptics, none can completely cure the patient nor prevent future episodes of convulsions, which thereby substantiate the necessity to develop newer and more effective anti-epileptic drugs.

The presence of prostaglandins in the mammalian brain is well-documented and prostaglandins are either directly or indirectly involved with neuronal activity. ${ }^{6}$ It has been known since long time that levels of cyclooxygenase (COX) and prostaglandins (PGs) are found to elevated in brain during or after induction of seizures in animal models, it was hypothesized that COX-inhibitors reduces seizures by inhibiting the synthesis of prostaglandins. ${ }^{7,8}$ Based on previous studies, phenytoin is known to upregulate P-glycoprotein (Pgp) levels in the rat brain capillaries, leading to pumping out of phenytoin from the brain. This upregulation of PG appears to be responsible for development of resistance to the antiepileptic, phenytoin. ${ }^{9-11}$ Celecoxib on the contrary, prevented this Pgp upregulation in rat brain capillaries. ${ }^{12,13}$ This action of celecoxib on Pgp expression is the underlying mechanism for suggesting the potentiation of anticonvulsant effect of phenytoin by celecoxib. ${ }^{14}$

Thus, the present study is undertaken to investigate the anticonvulsant activity of celecoxib and also to determine whether it potentiates the anticonvulsant effect of phenytoin in rat models of maximal electroshock seizure (MES) induced tonic convulsions.

\section{METHODS}

Seizures were induced in Albino rats by maximum electroshock method using electro-convulsiometer. The anticonvulsant effect of celecoxib in 3 graded doses and also of celecoxib (ED $\mathrm{E}_{50}$, calculated to be $20 \mathrm{mg} / \mathrm{kg}$ ) in combination with phenytoin (subanticonvulsant dose, calculated to be $6.25 \mathrm{mg} / \mathrm{kg}$ ) was assessed on this model. The anticonvulsant effects of the above 4 groups were compared with that of phenytoin (anticonvulsant dose i.e. $12.5 \mathrm{mg} / \mathrm{kg}$ ). ${ }^{15,16}$ The current study was given approval by the institutional animal ethics committee.

Male and female Wister Albino rats which weighed from $100 \mathrm{gm}$ to $200 \mathrm{gm}$ were utilized for this study. Rats in the animal house were kept in polypropylene cages at controlled temperature set between 20 to $24^{\circ} \mathrm{C}$ and the relative humidity set between 50 to $60 \%$ with standard 12 hour light-dark cycle beginning at 6.00 a.m. Standard pellet diet and water were provided to the rats as and when required. The chemicals and drugs used for the test method were celecoxib (Zydus Cadilla Pharmaceuticals), phenytoin (Zydus Neurosciences) and polyethylene glycol (SD Fine chem. Limited). Individual doses of the drugs to be administered were calculated for each rat according to their body weight and the drug was delivered to the rat through intra-peritoneal (IP) route. Also, the $\mathrm{ED}_{50}$ of celecoxib and the subanticonvulsant dose of phenytoin was determined in the pilot study. ${ }^{17}$

\section{MES method}

MES method of evaluating anti-seizure activity of a drug against generalized tonic-clonic seizures (grandmal seizures). Screening of rats was done one day prior to the test by subjecting to maximal electroshock using an electroconvulsiometer with an alternating current of 150 $\mathrm{mA}$ intensity for 0.2 seconds using trans-auricular electrodes. 42 rats which were screened positive for MES seizures, identified by the development of characteristic tonic-clonic seizures were selected and then randomly allocated to 7 groups with 6 rats in each group (Table 1). Rats were kept in separate polypropylene cages for conditioning them to the laboratory environment for 3 days and to avoid any possible kindling effect. The night before the experiment, food was withheld but water was allowed freely. On the day of the MES test, the drug solutions to be injected were freshly prepared in the morning and administered to the rats via IP route. After 40 minutes of drug administration, rats were subjected to an electrical stimulus (alternating current of $150 \mathrm{~mA}$ intensity for 0.2 sec through trans-auricular electrodes, originating from the electro-convulsiometer) to induce maximal seizures of its hind limbs, with tonic extension as the endpoint of the test. ${ }^{17}$ Experimental procedure was performed at nearly the same time each day. The 2 main parameters observed were onset of tonic hind limb extension (THLE) and duration of THLE (Table 1).

Delay in the onset of THLE and reduction in the duration of THLE by the drug were taken as the primary deciding parameters for determining the drug's anti-seizure effect. ${ }^{17}$

Alleviation in the above 2 parameters by celecoxib in 3 doubling doses $(10,20$ and $40 \mathrm{mg} / \mathrm{kg})$ and also by combination of celecoxib (ED $\mathrm{E}_{50}$ i.e. $20 \mathrm{mg} / \mathrm{kg}$ ) in combination with phenytoin (sub-anticonvulsant dose i.e. $6.25 \mathrm{mg} / \mathrm{kg}$ ) were compared with that of control (normal saline, $2.5 \mathrm{ml} / \mathrm{rat}$ ) and phenytoin (anticonvulsant dose i.e. $12.5 \mathrm{mg} / \mathrm{kg})^{15,16}$

\section{Statistical analysis}

Results were conveyed as mean \pm standard error of mean. One-way analysis of variance (ANOVA) was used for the statistical analysis of data, followed by post-hoc analysis done by least significant difference (LSD) test for multiple comparisons. A probability value of $\mathrm{p}<0.05$ was considered as significant.

\section{RESULTS}

Pretreatment with 2 doses of celecoxib (20 and $40 \mathrm{mg} / \mathrm{kg}$, administered IP 40 minutes before MES) significantly delayed the onset of THLE $(5.52 \pm 0.2$ and $6.43 \pm 0.26$ seconds respectively) in comparison to normal saline pretreatment $(3.45 \pm 0.28 \mathrm{sec})$. The standard drug phenytoin 
sodium in doses of $6.25 \mathrm{mg} / \mathrm{kg}$ and $12.5 \mathrm{mg} / \mathrm{kg}$ (administered IP 40 minutes before MES) also delayed the onset of THLE $(6.56 \pm 0.27$ and $7.26 \pm 0.26$ seconds respectively) in comparison to normal saline $(3.45 \pm 0.2$ seconds) (Table 1).

Pretreatment with 2 doses of celecoxib (20 and $40 \mathrm{mg} / \mathrm{kg}$, IP 40 minutes before MES) significantly decreased the duration of THLE $(8.97 \pm 0.30$ and $5.10 \pm 0.18$ seconds respectively) in comparison to normal saline pretreatment (12.90 \pm 0.16 seconds). The standard drug phenytoin in doses of $6.25 \mathrm{mg} / \mathrm{kg}$ and $12.5 \mathrm{mg} / \mathrm{kg}$ IP also decreased the duration of THLE $(4.72 \pm 0.17,2.32 \pm 0.20$ seconds respectively) in comparison to normal saline pretreatment (12.90 \pm 0.16 seconds) (Table 1$)$.

There was no significant difference in the delay in the onset of THLE between the 7th group i.e. celecoxib $20 \mathrm{mg} / \mathrm{kg}$ and phenytoin sodium $6.25 \mathrm{mg} / \mathrm{kg}(6.98 \pm 0.12$ seconds) when compared with 5 th group i.e. phenytoin $6.25 \mathrm{mg} / \mathrm{kg}$ alone (6.57 \pm 0.27 seconds) (Table 1$)$. However, there was a significant difference in the reduction of duration of THLE between the 7th group i.e. celecoxib $20 \mathrm{mg} / \mathrm{kg}$ and phenytoin sodium $6.25 \mathrm{mg} / \mathrm{kg}(3.82 \pm 0.16$ seconds) when compared with 5 th group i.e. phenytoin $6.25 \mathrm{mg} / \mathrm{kg}$ alone (4.72 \pm 0.17 seconds) (Table 1$)$.

Table 1: Effect of drugs on maximum electroshock induced seizures in Albino rats.

\begin{tabular}{|lllll|}
\hline Group & Drug (dose $\mathbf{m g} / \mathrm{kg})$ & \multicolumn{2}{l}{ Time in various phases of convulsions (seconds) } & Recovered/death \\
\hline $\mathbf{1}$ & Normal saline $(2.5 \mathrm{ml} / \mathrm{rat})$ & $3.45 \pm 0.29$ & $12.90 \pm 0.16$ & Recovered \\
\hline $\mathbf{2}$ & Celecoxib (10) & $3.87 \pm 0.20$ & $11.44 \pm 0.26$ & Recovered \\
\hline $\mathbf{3}$ & Celecoxib (20) & $5.52 \pm 0.26^{*}$ & $8.97 \pm 0.30^{*}$ & Recovered \\
\hline $\mathbf{4}$ & Celecoxib (40) & $6.43 \pm 0.26^{*}$ & $5.10 \pm 0.18^{*}$ & Recovered \\
\hline $\mathbf{5}$ & Phenytoin (6.25) & $6.57 \pm 0.27^{*}$ & $4.72 \pm 0.17 *$ & Recovered \\
\hline $\mathbf{6}$ & Phenytoin (12.5) & $7.62 \pm 0.26^{*}$ & $2.32 \pm 0.20^{*}$ & Recovered \\
\hline $\mathbf{7}$ & Celecoxib (20) + phenytoin (6.25) & $6.98 \pm 0.12^{*}$ & $3.82 \pm 0.16^{*}$ & Recovered \\
\hline
\end{tabular}

Values are expressed as mean \pm SD of mean of 6 rats. One way ANOVA followed by LSD test for post-hoc analysis $(* \mathrm{p}<0.05$ is taken as significant value).

\section{DISCUSSION}

Celecoxib (20 mg/kg), celecoxib (40 mg/kg), phenytoin $(6.25 \mathrm{mg} / \mathrm{kg})$, phenytoin $(12.5 \mathrm{mg} / \mathrm{kg})$ and celecoxib $(20$ $\mathrm{mg} / \mathrm{kg})$ and phenytoin $(6.25 \mathrm{mg} / \mathrm{kg})$ pre-treatment significantly $(\mathrm{p}<0.05)$ delayed the onset of THLE and also reduced the duration of THLE when compared to normal saline (NS) pre-treatment, indicating that the drug in the above 5 groups in their respective doses have anticonvulsant effect in rats. Also, phenytoin $(12.5 \mathrm{mg} / \mathrm{kg})$ IP pretreatment showed a significantly greater $(\mathrm{p}<0.05)$ delay in onset of THLE and greater reduction in the duration of THLE when compared to celecoxib $(40 \mathrm{mg} / \mathrm{kg})$ IP pretreatment, suggesting that phenytoin (anticonvulsant dose) is a more potent anticonvulsant when compared to celecoxib (at its maximum tolerated dose i.e. $40 \mathrm{mg} / \mathrm{kg}$ ) in MES model in rats. The above findings indicate that COX2 inhibition has anticonvulant effect, as observed in the MES induced seizures in Albino rats.

The addition of celecoxib $(20 \mathrm{mg} / \mathrm{kg})$ to phenytoin $(6.25$ $\mathrm{mg} / \mathrm{kg}$ ) did not show any significant difference in the delaying of onset of THLE when compared to phenytoin alone at $6.25 \mathrm{mg} / \mathrm{kg}$. However, the addition of celecoxib $(20 \mathrm{mg} / \mathrm{kg})$ to phenytoin $(6.25 \mathrm{mg} / \mathrm{kg})$ significantly decreased the duration of THLE when compared to phenytoin alone at $6.25 \mathrm{mg} / \mathrm{kg}$, indicating the potentiation of anticonvulsant effect of phenytoin by celecoxib in Albino rats.

Shafiq et al reported similar findings with celecoxib on MES induced convulsions. ${ }^{16}$ Another study which demonstrated anticonvulsant effect of celecoxib was done by Jung et al, who proved that oral celecoxib reduced the duration of seizures in pilocarpine induced rat models. ${ }^{18} \mathrm{~A}$ recent study by Citraro et al showed that selective COX-2 inhibitor etoricoxib possesses protective activity against generation of absence seizures in WAG/Rij rats. ${ }^{19}$ Another study down by Dir et al against picrotoxin-induced seizures also showed that rofecoxib prolonged the time of onset of seizures and also reduced the duration of seizures. ${ }^{20}$ It was reported in an earlier study that non selective COX inhibitors like aspirin, paracetamol and diclofenac sodium also antagonized the MES and pentylenetetrazole induced convulsions in mice. ${ }^{21}$

The present study also showed that celecoxib potentiates the anticonvulsant effect of phenytoin, which is similar to findings from two studies done by Dhir et al who reported potentiation effect of another selective COX-2 inhibitor, rofecoxib on different anti-epileptics i.e. tiagabine and topiramate respectively on pentylenetetrazol-induced convulsions in mice. ${ }^{22,23}$ Kaminski et al reported that nonselective COX inhibitors like ibuprofen and piroxicam potentiated the anticonvulsive effect of phenytoin against MES induced seizures in mice. ${ }^{24}$

From the above MES test findings, it can be deduced that COX-2 levels are increased in seizures, since its inhibition was found to be beneficial in alleviating seizures. It is well known fact that COX-2 is rapidly induced following a proinflammatory event with a subsequent release of mediators of inflammation, prostaglandins. The levels of pro-inflammatory mediators like prostaglandin E2 (PGE2), 
interleukin-1 $\beta$ (IL-1 $\beta$ ) and tumour necrosis factor- $\alpha$ (TNF$\alpha$ ) increased in epilepsy as was demonstrated in several studies done in animals. ${ }^{25}$ In neuroinflammation, activated microglia was shown to release IL-1 $\beta$ which led to the induction of COX-2 and synthesis of PGE2 in astrocytes of mice brain. ${ }^{26}$ TNF- $\alpha$ caused induction of $\mathrm{COX}-2$ and synthesis of PGE2 leading to an increased vascular permeability and cellular alterations in capillary endothelial cells of bovine brain. ${ }^{27}$ Production of PGE2, was found to be increased along with COX-2 induction following rodent models of epilepsy in studies done previously. ${ }^{28,29}$

PGE2 binds to 4 types of $G$ protein-coupled receptors (GPCRs), which are EP1, EP2, EP3, and EP4. Activation of EP1 and EP2 types results in an increased calcium ion influx leading to enhanced release of glutamate presynaptically. These 2 types of GPCRs also play an important part in neuroinflammation. ${ }^{30,31}$ Blocking of EP2 receptor using 3-aryl-acrylamide derivatives led to attenuation of status epilepticus induced neuroinflammation and neuronal injury in rats. ${ }^{32}$

COX-2 inhibitors inhibited the synthesis of proinflammatory cytokines, PGE2 and IL-1 $\beta$ in the brain hippocampus of rats, thereby reducing neuroinflammation. It is thus proposed that the anticonvulsive effect of COX-2 inhibitors is because of a reduction in the production of PGE2 levels. This reduced PGE2 further causes a decreased activation of EP receptors which lowers calcium ion influx and lowers the release of the glutamate, an excitatory neurotransmitter, thus preventing the seizures. ${ }^{33}$ Both IL- $1 \beta$ and TNF- $\alpha$ expression was also decreased by indomethacin, a non-selective COX inhibitor in pilocarpine induced status epilepticus in rat hippocampus, thus indicating a regulatory action of $\mathrm{COX}-2$ on the above proinflammatory cytokines. ${ }^{34}$ Kunz and Oliw proved that rofecoxib prevented neuroinflammation in the rat hippocampus in kainate induced epilepsy. ${ }^{35}$ Oliveira et al demonstrated the anticonvulsant effect of celecoxib, which was reversed by intracerebroventricular administration of PGE2 and reported that PGE2 induces neuroinflammation and has epileptogenic properties. ${ }^{36}$ Polascheck et al reported that parecoxib (another COX-2 inhibitor) pretreatment for 18 days, followed by pilocarpine-induced status epilepticus prevented the subsequent increase in PGE2 and reduced seizure severity in the rat hippocampus and piriform cortex. ${ }^{37}$ Thus, neuroprotection was offered by COX-2 inhibitors in rat models of epilepsy.

P-glycoprotein (Pgp) upregulation pumps out drugs from the brain, which seems to the underlying mechanism for the development of resistance to phenytoin. ${ }^{38}$ Multiple attempts to selectively inhibit Pgp pump to improve pharmacotherapy in epilepsy have been attempted in the past. ${ }^{39,40}$ It was found that phenytoin pretreatment for 21 days upregulated Pgp in capillary endothelial vessels in rats. ${ }^{10}$ In a recent study, the upregulation of Pgp by phenytoin was demonstrated using a radiopharmaceutical containing carbon C-11 N-desmethyl-lopermaide and visualised under positron emission tomography (PET). ${ }^{11}$

Celecoxib was found to prevent Pgp upregulation in rat brain capillaries in pilocarpine induced status epilepticus model. ${ }^{13}$ COX-2 inhibitors like NS-398 and SC-58236 stimulated delivery of phenytoin in brain of epileptic rats having down-regulated Pgp. ${ }^{14}$ The levels of phenytoin in the brain was significantly increased by $\mathrm{COX}-2$ inhibition in rats with recurrent seizures by suppressing Pgp expression in chronic epileptic rats, suggesting that COX2 inhibitors increases phenytoin delivery to the target sites in the brain, thereby explaining its potentiating effect. ${ }^{14}$

\section{CONCLUSION}

Celecoxib potentiated the anticonvulsant effect of phenytoin in rats. Further studies are required to establish the therapeutic role of using COX-2 inhibitors as effective potentiating agents when used in combination with existing antiepileptic drugs, which could be beneficial in refractory epilepsy. However, the limitation to the long term use of a COX-2 inhibitor is its increased cardiovascular risk, for which newer COX-2 inhibitors are required to be developed with favourable risk-benefit ratio. Discovering newer drugs which target pro-inflammatory cytokines involved in brain inflammation could also prove to be a promising therapeutic strategy in refractory epilepsy.

\section{ACKNOWLEDGEMENTS}

Authors would like to thank all the faculty and postgraduates of pharmacology department.

Funding: No funding sources

Conflict of interest: None declared

Ethical approval: The study was approved by the Institutional Ethics Committee

\section{REFERENCES}

1. Epilepsy. World Health Organization. 2019. Available at: https://www.who.int/news-room/factsheets/detail/epilepsy. Accessed on 20 June 2019.

2. Fisher RS, van Emde Boas W, Blume W, Elger C, Genton P, Lee P, Engel J. Epileptic seizures and epilepsy: definitions proposed by the international league against epilepsy (ILAE and the International Bureau for Epilepsy (IBE). Epilepsia. 2005;46:470-2.

3. Kwan P, Arzimanoglou A, Berg AT, Brodie MJ, Allen Hauser W, Mathern G. Definition of drug resistant epilepsy: consensus proposal by the ad hoc Task Force of the ILAE Commission on Therapeutic Strategies. Epilepsia. 2010;51:1069-77.

4. Schiller Y, Najjar Y. Quantifying the response to antiepileptic drugs: effect of past treatment history. Neurology. 2008;70:54-65.

5. Luciano AL, Shorvon SD. Results of treatment changes in patients with apparently drug-resistant chronic epilepsy. Ann Neurol. 2007;62:375-81. 
6. Loscher, W. Current status and future directions in the pharmacotherapy of epilepsy. Trends Pharmacol Sci. 2002;23(3):113-8.

7. Wallenstein MC, Mauss EA. Effect of prostaglandin synthetase inhibitors on experimentally induced convulsions in rats. Pharmacology. 1984;29:85.

8. Wolfe LS. Possible role of prostaglandins in the nervous system. Adv Neurochem. 1975;1:1.

9. Loscher W, Potschka H. Role of drug efflux transporters in the brain for drug disposition and treatment of brain diseases. Prog Neurobiol. 2005;76:22-76.

10. Wen T, Liu YC, Yang HW, Liu HY, Liu XD, Wang GJ, Xie L. Effect of 21-day exposure of phenobarbital, carbamazepine and phenytoin on P-glycoprotein expression and activity in the rat brain. J Neurol Sci. 2008;270:99-106.

11. Moerman L, Wyffels L, Slaets D, Raedt R, Boon P, De Vos F. Antiepileptic drugs modulate Pglycoproteins in the brain: a mice study with (11)Cdesmethylloperamide. Epilepsy Res. 2011;94:18-25.

12. Bauer B, Hartz AM, Pekcec A, Toellner K, Miller DS, Potschka H. Seizure-induced up-regulation of Pglycoprotein at the blood-brain barrier through glutamate and cyclooxygenase-2 signaling. Mol Pharmacol. 2008;73:1444-53.

13. Zibell G, Unkruer B, Pekcec A, Hartz AM, Bauer B, Miller DS, Potschka H. Prevention of seizure induced up-regulation of endothelial P-glycoprotein by COX2 inhibition. Neuropharmacology.2009;56:849-55.

14. van Vliet EA, Zibell G, Pekcec A, Schlichtiger J, Edelbroek PM, Holtman L, Aronica E, Gorter JA, Potschka H. COX-2 inhibition controls P-glycoprotein expression and promotes brain delivery of phenytoin in chronic epileptic rats. Neuropharmacology. 2010;58:404-12.

15. Löscher W. The pharmacokinetics of antiepileptic drugs in rats: consequences for maintaining effective drug levels during prolonged drug administration in rat models of epilepsy. Epilepsia. 2007;48(7):1245-58.

16. Shafiq N, Malhotra S, Pandhi P. Anticonvulsant action of celecoxib (alone and in combination with subthreshold dose of phenytoin) in electroshock induced convulsion. Method Find Ex. Clin Pharmacol. 2003;25(2):87-90.

17. Castel-Branco MM, Alves GL, Figueiredo IV, Falcão AC, Caramona MM. The maximal electroshock seizure (MES) model in the preclinical assessment of potential new antiepileptic drugs. Methods Find Exp Clin Pharmacol. 2009;31(2):101-6.

18. Jung KH, Chu K, Lee ST, Kim J, Sinn DI, Kim JM, Park DK, Lee JJ, Kim SU, Kim M, Lee SK, Roh JK. Cyclooxygenase-2 inhibitor, celecoxib, inhibits the altered hippocampal neurogenesis with attenuation of spontaneous recurrent seizures following pilocarpineinduced status epilepticus. Neurobiol Dis. 2006;23:237-46.

19. Citraro R, Leo A, Marra R, De Sarro G, Russo E. Antiepileptogenic effects of the selective COX-2 inhibitor etoricoxib, on the development of spontaneous absence seizures in WAG/Rij rats. Brain Res Bull. 2015;113:1-7.

20. Dhir A, Naidu PS, Kulkarni SK. Effect of cyclooxygenase-2 (COX-2) inhibitors in various animal models (bicuculline, picrotoxin, maximal electroshock induced convulsions) of epilepsy with possible mechanism of action. Indian J Exp Biol. 2006;44:286-91.

21. Srivastava AK, Gupta YK. Aspirin modulates the anticonvulsant effect of diazepam and sodium valproate in pentylenetetrazole and maximal electroshock induced seizures in mice. Indian $\mathrm{J}$ Physiol Pharmacol. 2001;45:475-80.

22. Dhir A, Kulkarni SK. Rofecoxib, a selective cyclooxygenase-2 (COX-2) inhibitor potentiates the anticonvulsant activity of tiagabine against pentylenetetrazol-induced convulsions in mice. Inflammopharmacology. 2006;14(5-6):222-5.

23. Dhir A, Akula KK, Kulkarni SK. Rofecoxib potentiates the anticonvulsant effect of topiramate. Inflammopharmacology. 2008;16(2):83-6.

24. Kaminski R, Kozicka M, Parada-turska J, Dziki M, Kleinrok Z, Turski WA, et al. Effect of non-steroidal anti-inflammatory drugs on the anticonvulsive activity of valproate and diphenyl hydantoin against maximal electroshock induced seizures in mice. Pharmacol Res. 1998;37:375-81.

25. Dey A, Kang X, Qiu J, Du Y, Jiang J. AntiInflammatory Small Molecules To Treat Seizures and Epilepsy: From Bench to Bedside. Trends Pharmacol Sci. 2016;37(6):463-84.

26. Molina-Holgado E, Ortiz S, Molina-Holgado F, Guaza C. Induction of COX-2 and PGE(2) biosynthesis by IL-1beta is mediated by PKC and mitogen-activated protein kinases in murine astrocytes. Br J Pharmacol. 2000;131:152-9.

27. Mark KS, Trickler WJ, Miller DW. Tumor necrosis factor-alpha induces cyclooxygenase-2 expression and prostaglandin release in brain microvessel endothelial cells. J Pharmacol Exp Ther. 2001;297:1051-8.

28. Kawaguchi K, Hickey RW, Rose ME, Zhu L, Chen J, Graham SH. Cyclooxygenase-2 expression is induced in rat brain after kainate-induced seizures and promotes neuronal death in CA3 hippocampus. Brain Res. 2005;1050:130-7.

29. Takemiya T, Maehara M, Matsumura K, Yasuda S, Sugiura H, Yamagata K. Prostaglandin E2 produced by late induced $\mathrm{COX}-2$ stimulates hippocampal neuron loss after seizure in the $\mathrm{CA} 3$ region. Neurosci Res. 2006;56:103-10.

30. Nishihara I, Minami T, Watanabe Y, Ito S, Hayaishi O. Prostaglandin E2 stimulates glutamate release from synaptosomes of rat spinal cord. Neurosci Lett. 1995;196:57-60.

31. Sang N, Zhang J, Marcheselli V, Bazan NG, Chen C. Postsynaptically synthesized prostaglandin E2 (PGE2) modulates hippocampal synaptic transmission via a presynaptic PGE2 EP2 receptor. J Neurosci. 2005;25:9858-70. 
32. Jiang J, Quan Y, Ganesh T, Pouliot WA, Dudek FE, Dingledine R. Inhibition of the prostaglandin receptor EP2 following status epilepticus reduces delayed mortality and brain inflammation. Proc Natl Acad Sci USA. 2013;110:3591-6.

33. Lin TY, Lu CW, Wang CC, Huang SK, Wang SJ. Cyclooxygenase 2 inhibitor celecoxib inhibits glutamate release by attenuating the PGE2/EP2 pathway in rat cerebral cortex endings. J Pharmacol Exp Ther. 2014;351:134-45.

34. Vieira MJ, Perosa SR, Argaaaraz GA, Silva JA Jr, Cavalheiro EA, Graca Naffah- Mazzacoratti $M$. Indomethacin can downregulate the levels of inflammatory mediators in the hippocampus of rats submitted to pilocarpine-induced status epilepticus. Clinics. 2014;69:621-6.

35. Kunz T, Oliw EH. The selective cyclooxygenase-2 inhibitor rofecoxib reduces kainate-induced cell death in the rat hippocampus. Eur J Neurosci. 2001b;13:56975.

36. Oliveira MS, Furian AF, Royes LF, Fighera MR, Fiorenza NG, Castelli M, Machado P, Bohrer D, Veiga M, Ferreira J, Cavalheiro EA, Mello CF. Cyclooxygenase-2/PGE2 pathway facilitates pentylenetetrazol-induced seizures. Epilepsy Res. 2008;79:14-21.
37. Polascheck N, Bankstahl M, Löscher W. The COX-2 inhibitor parecoxib is neuroprotective but not antiepileptogenic in the pilocarpine model of temporal lobe epilepsy. Exp Neurol. 2010;224:219-33.

38. Loscher W, Potschka H. Role of drug efflux transporters in the brain for drug disposition and treatment of brain diseases. Prog Neurobiol. 2005;76:22-76.

39. Brandt C, Bethmann K, Gastens AM, Loscher W. The multidrug transporter hypothesis of drug resistance in epilepsy: Proof-of-principle in a rat model of temporal lobe epilepsy. Neurobiol Dis. 2006;24:202-11.

40. van Vliet EA, van Schaik R, Edelbroek PM, Redeker S, Aronica E, Wadman WJ, Marchi N, Vezzani A, Gorter JA. Inhibition of the multidrug transporter Pglycoprotein improves seizure control in phenytointreated chronic epileptic rats. Epilepsia. 2006;47:67280 .

Cite this article as: Nadeem MN, Maqdoom M. Potentiation of anticonvulsant effect of phenytoin by celecoxib against maximum electroshock induced convulsions in albino rats. Int $\mathbf{J}$ Basic Clin Pharmacol 2020;9:1491-6. 